\title{
Population-Based Strategy for Preventing Diabetes and its Complications
}

\author{
Shaw Watanabe, MD, PhD ${ }^{1,2^{*}}$ \\ 'Lifescience Promoting Association, Daikyo-cho 25-3-1004, Shinjuku-ku, Tokyo 160-0015, Japan \\ ${ }^{2}$ Asia Pacific Clinical Nutrition Society (APCNS), Department of Food Science and Nutrition, Zhejiang University, 866 Yu-Hang-Tang Road, Hangzhou 310058 , China
}

*Corresponding author

Shaw Watanabe, MD, PhD

Lifescience Promoting Association, Daikyo-cho 25-3-1004, Shinjuku-ku, Tokyo 160-0015, Japan; Fax:+8I-3-5379-7786; E-mail: watashaw@lifescience.or.jp

\section{Article information}

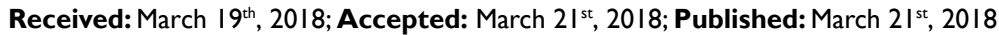

\section{Cite this article}

Watanabe S. Population-based strategy for preventing diabetes and its complications. Diabetes Res Open J. 20I8; 4(I): el-e4. doi: I0. I7I40/DROJ-4-e0II

\section{“PROPER OR NOT" OF INTENSIVE THERAPY}

A recent report from the American College of Physicians (ACP) should cause a paradigm change for the treatment of diabetic patients. ${ }^{1}$ The main purpose of diabetes therapy is the prevention of complications. ${ }^{2}$ The endpoint of many clinical trials is to lower blood glucose levels, but intensive treatments aimed at lowering the $\mathrm{HbA} 1 \mathrm{c}$ to less than $6.5 \%$ are often accompanied by hypoglycemia as a side effect. At the same time, intensive regimens have not shown a reduction of cardiovascular complications in the longterm..$^{3-7}$ For example, the action to control cardiovascular risk in diabetes (ACCORD) trial was prematurely discontinued, following the observation of an increase in overall mortality, cardiovascular-related deaths, and severe hypoglycemic events. ${ }^{3}$ The action in diabetes and vascular disease; preterAx and diamicroN-MR controlled evaluation (ADVANCE) study also failed to show a statistically significant clinical benefit, while more adverse effects were seen among those who achieved a median HbA1c level of $6.4 \%{ }^{4}$ More intensive treatments with tight glycemic control targets are more costly and associated with increased patient burdens. Only Hollan et $\mathrm{al}^{8}$ reported a long-term benefit with intensive therapy in the United Kingdom prospective diabetes study (UKPDS) after 10 years of intervention.

Multidrug intervention trials were also reviewed. The Steno-2 study planned to examine if multifactorial interventions (including behavior interventions) meant to decrease blood glucose, blood pressure and lipids in type- 2 diabetes patients, could reduce the risks of microangiopathy, macroangiopathy, and premature deaths. ${ }^{9}$ After a median follow-up of 13.3 years, an overall $20 \%$ absolute reduction in the risk of death (or decreased hazard ratio of 0.54 for death) was observed in the intensive-therapy group, as compared with the conventional-therapy group.
In the Steno-2 study; however, the number of subjects was small and the average $\mathrm{HbA1c}$ percentage also remained at a considerably higher level than the target value in the intensified therapy group. ${ }^{10-12}$ Accordingly, the J-Doit-3 study was planned in Japan, in which 2542 patients were randomly assigned either to ordinary therapy or intensive therapy, and followed-up for a median period of 8.5 years. ${ }^{13,14}$ The goals of the intensive therapy and ordinary therapy were set as follows: HbA1c $(<6.2 \% v$ s. $<6.9 \%)$, blood pressure $(<120 / 75 \mathrm{mmHg} v s .<130 / 80 \mathrm{mmHg})$, LDL cholesterol $(<80 \mathrm{mg} / \mathrm{dL} v$ s. $<120 \mathrm{mg} / \mathrm{dL})$, HDL cholesterol $(\geq 40 \mathrm{mg} / \mathrm{dL} v \mathrm{~s}$. $\geq 40 \mathrm{mg} / \mathrm{dL})$, triacylglycerol (<120 mg/dL vs. $<150 \mathrm{mg} / \mathrm{dL})$, BMI $(\leq 22 v$ s. $\leq 24)$, respectively. A primary outcome occurred in 109 patients in the intensive therapy group and in 133 patients in the conventional therapy group (hazard ratio [HR] 0.81, $p=0.094$ ). Allcause mortality (HR 1.01, $p=0.95$ ) and coronary events (myocardial infarction, coronary artery bypass surgery, and percutaneous transluminal coronary angioplasty; HR $0.86, p=0.44$ ) did not differ between groups, but cerebrovascular events (stroke, carotid endarterectomy, percutaneous transluminal cerebral angioplasty, and carotid artery stenting) were significantly less frequent in the intensive therapy group (HR $0.42, p=0.02$ ). During a median follow-up of 8.5 years, lowered risks of cerebral hemorrhage and nephropathy were observed, but hypoglycemia occurred in $41.1 \%$ patients in the intensive treatment $v$ s. $22.3 \%$ in the control group.

\section{IDENTIFICATION OF HIGH-RISK DIABETIC PATIENTS FOR INTENSIVE THERAPY}

The J-Doit-3 study suggested that multidrug therapy prevented renal insufficiency. Thus, in a public seminar "Challenge to overcome kidney disease", the Japan Kidney Society and the Japan Diabetes Society jointly recommended that family doctors refer patients to a specialist when diabetic kidney disease is suspected. ${ }^{15}$ 
Every year in Japan, more than 10,000 patients progress to renal failure and receive hemodialysis as complications of diabetes. ${ }^{16}$ The medical cost of treating a total of 300,000 patients with dialysis is expected to exceed 1.5 trillion yen. Prevention of DKD is thus cost-saving public health priority.

Recently, Scandinavian researchers have categorized diabetes mellitus into three severe and two mild forms. ${ }^{17}$ Data were consolidated between five cohorts: Swedish All New Diabetics in Scania, Scania Diabetes Registry, All New Diabetics in Uppsala, Diabetes Registry Vaasa, and Malmö Diet and Cancer Cardiovascular Arm. They used six variables for the cluster analysis of 8980 patients, all of whom were newly diagnosed with diabetes between 2008 and 2016. Variables included: the presence of glutamic acid decarboxylase antibody (GADA); age at diagnosis; $\mathrm{BMI}$; $\mathrm{HbA}_{1 \mathrm{c}}$; homeostatic model assessment 2 (HOMA2) and insulin-resistance (HOMA2-IR), based on C-peptide concentrations.

The analysis revealed the presence of five clusters of diabetes. Cluster 1: Severe autoimmune diabetes (SAID), Cluster 2: Severe insulin-deficient diabetes (SIDD), Cluster 3: Severe insulinresistant diabetes (SIRD), Cluster 4: Mild obesity-related diabetes (MOD) and Cluster 5: Mild age-related diabetes (MARD). Cluster 2 patients had substantially higher $\mathrm{HbA}_{1 \mathrm{c}}$ levels and diabetic retinopathy was more common than in other clusters. Patients in cluster 3 had a substantially higher risk of end-stage renal disease. Such a clinically useful stratification is an important step towards tailormade precision medicine in diabetes. A low-protein diet is effective to reverse the progression to kidney failure, and low-protein rice is easily available to decrease protein from diet. ${ }^{18-20}$

\section{IMPORTANCE OF PRIMARY PREVENTION IN AGING SOCIETY [}

In Japan, the number of diabetic patients has been steadily increasing, with 604 million $(6.6 \%)$ in 1990,714 million $(7.1 \%)$ in 2000 , 830 million $(7.9 \%)$ in 2010 , and it is estimated to rise to 971 million $(9.8 \%)$ in $2030 .{ }^{21}$ Worldwide, the number of diabetic patients is about 425 million, including 110 million in China, 73 million in India, and 30 million in United States. ${ }^{22}$

Changes in lifestyle, such as sedentary life and western style high-calorie diet, and resulting obesity account for the increase seen in diabetic patients. Furthermore, in Japan the aging of the population is an additional risk, reflecting stable changes in the age adjustment. Japanese people tend to become diabetic even if they are mildly obese, compared with West Caucasians, i.e., 7-8\% of Caucasians become diabetic at a BMI 30, while one fourth becomes diabetic at the same BMI in Japan. ${ }^{23}$

Obese people are a pre-diabetic population, where a population approach could be effective through the control of intake energy sources and an increase in physical activity. ${ }^{24}$ However, this is difficult to achieve in most patients unwilling to change their lifestyle.

A physiological deterioration is commonly observed in elderly people, involving in particular cardiac, renal, and respiratory functions, and muscle strength. Decreasing insulin secretion being just one aspect of the problem, an integrated strategy is necessary to cover the full range of diabetes complications. Simple hyperglycemia without hypertension and renal failure could easily be controlled by dietary and physical activity. ${ }^{25}$

Multiple chronic conditions are common in older populations. The frequency of polypharmacy and potential drug interactions make it difficult to balance the benefits and harms of therapy in older patients. For patients with multiple comorbid conditions, (e.g., renal failure, liver failure, end-stage disease, cognitive impairment, advanced microvascular or macrovascular complications, or any other conditions that limit life expectancy), the harms of setting more stringent $\mathrm{HbA} 1 \mathrm{c}$ targets outweigh their benefits. More recent guidelines discuss the role of less intensive treatment for older patients, to minimize symptoms rather than achieve a specific HbA1c target. ${ }^{26-28}$

The ACP has proposed that the treatment of diabetes for the older person aged more than 80 years should primarily be adjusted to their quality of life (QOL). ${ }^{1}$ The American Diabetes Association (ADA) guidelines of 2017 raise psychosocial issues in a number of areas, including the self-management of diabetes and the management of co-morbid conditions. Doctors should become familiar with existential therapy or holistic treatment, among techniques that can achieve behavioral changes in patients.

\section{DIETARY INTERVENTION AS A POPULATION STRATEGY |-}

The cross-sectional study on dietary habit and health (GENKI study) clarified the characteristics of obese people and brown rice eaters among 6000 participants. ${ }^{29,30}$ Obese people have lifestylerelated diseases, such as diabetes, hypertension, hyperlipidemia, gout, bronchitis and gallstones, and they typically take medications for these diseases with an increased odds ratio (OR) between 2 and 3. They felt unhealthy and lost vivid feeling in daily life. They spent a sedentary life, preferring fatty foods and meat, to vegetables, and ate until full stomach.

On the contrary, brown rice eaters consume significantly more carrots, green yellow vegetables, radish, ginger, burdock, lotus root, sweet potatoes, yam, salty plum pickles (umeboshl), sesame, peanut, chestnut, mushroom, dried mushroom (sbiitake), dried radish, dried seaweed (nor), kelp (konbu), red bean (azuki), and soy milk. They did not consume meat, but soy protein was substituted to meat and fish. They felt healthy and vivid, became better compared to the previous year, and showed low OR for lifestyle-related diseases $(\mathrm{OR}=$ around 0.3$)$.

It has been clarified in recent studies, that brown rice contains functional ingredients, such as dietary fibres, ferulic acids, GABA, and antioxidants. They keep a good balance of the bacterial flora and of the immune system. Considering that obesity is associated with various diseases, it is important to consider brown rice among interventions to control obesity. ${ }^{31}$ 


\section{REFERENCES}

1. Americal College of Physicians. Clinical Guidelines and Recommendations. Web site. http://www.acponline.org/clinical-information/guidelines. Accessed March 18, 2017.

2. Ojo O. An overview of diabetes and its complications. Diabetes Res Open J. 2016; 2(2): e4-e6. doi: 10.17140/DROJ-2-e005

3. Gerstein HC, Miller ME, Genuth S, et al. ACCORD Study Group. Long-term effects of intensive glucose lowering on cardiovascular outcomes. N Engl J Med. 2011; 364: 818-828. doi: 10.1056/ NEJMoa1006524

4. Patel A, MacMahon S, Chalmers J, et al. ADVANCE Collaborative Group. Intensive blood glucose control and vascular outcomes in patients with type 2 diabetes. N Engl J Med. 2008; 358: 25602572. doi: 10.1056/NEJMoa0802987

5. Duckworth W, Abraira C, Moritz T, et al. VADT Investigators. Glucose control and vascular complications in veterans with type 2 diabetes. N Engl J Med. 2009; 360: 129-139. doi: 10.1056/NEJMoa0808431

6. UK Prospective Diabetes Study (UKPDS) Group. Effect of intensive blood-glucose control with metformin on complications in overweight patients with type 2 diabetes (UKPDS 34). Lancet. 1998; 352-854. doi: 10.1016/S0140-6736(98)07037-8

7. Hayward RA, Reaven PD, Wiitala WL, et al. VADT Investigators. Follow-up of glycemic control and cardiovascular outcomes in type 2 diabetes. N Engl J Med. 2015; 372: 2197-2206. doi: 10.1056/ NEJMoa1414266

8. Holman RR, Paul SK, Bethel MA, Matthews DR, Neil HA. 10 year follow-up of intensive glucose control in type 2 diabetes. $N$ Engl J Med. 2008; 359: 1577-1589. doi: 10.1056/NEJMoa0806470

9. Bajaj H, Zinman B. Diabetes: Steno-2 - a small study with a big heart. Nat Rev Endocrinol. 2016; 12(12): 692-694. doi: 10.1038/ nrendo.2016.172

10. Gaede P, Vedel P, Larsen N, Jensen GV, Parving HH, Pedersen $\mathrm{O}$. Multifactorial intervention and cardiovascular disease in patients with type 2 diabetes. N Engl J Med. 2003; 348(5): 383-393. doi: 10.1056/NEJMoa021778

11. Gæde P, Oellgaard J, Carstensen B, et al. Years of life gained by multifactorial intervention in patients with type 2 diabetes mellitus and microalbuminuria: 21 years follow-up on the Steno- 2 randomised trial. [Abstract taken from Diabetes Care. 2017; 40(Suppl 1): S75-S87.] Diabetologia. 2016; 59(11): 2298-2307. doi: 10.1007/ s00125-016-4065-6.

12. American Diabetes Association. Cardiovascular disease and risk management. Diabetes Care. 2017; 40(Suppl 1): S75-S87. PMID: 27979896. doi: $10.2337 / \mathrm{dc} 17-\mathrm{S} 012$
13. Ueki K, Sasako T, Kato M, et al. Design of and rationale for the Japan Diabetes Optimal Integrated Treatment study for 3 major risk factors of cardiovascular diseases (J-DOIT3): A multicenter, open-label, randomized, parallel-group trial. BMJ Open Diabetes Res Care. 2016 Jan 25; 4(1): e000123. doi: 10.1136/bmjdrc-2015-000123

14. J-DOIT3 Study Group. Effect of an intensified multifactorial intervention on cardiovascular outcomes and mortality in type 2 diabetes (J-DOIT3): An open-label, randomised controlled trial. Lancet Diabetes Endocrinol. 2017; 5(12): 951-964. doi: 10.1016/ S2213-8587(17)30327-3

15. Diabetes Resource Guide Japan. Revision of stage classification for DKD. Web site. www://dm-rg.net/news/2014/01/014349. html. Accessed March 18, 2017.

16. Japan Preventive Association of Life-style related Disease. Number of hemodialysis patients. Web site. www.seikatsusyukanbyo.com/statistics/2016/009096.php. Accessed March 18, 2017.

17. Ahlqvist E, Storm P, Karajamaki A, et al. Novel subgroups of adult-onset diabetes and their association with outcomes: A datadriven cluster analysis of six variables. Lancet Diabetes Endocrinol. 2018; doi: 10.1016/S2213-8587(18)30051-2

18. Watanabe S, Noburu M, Yasunari M, Ideura T. A cross-sectional study on the effects of long term very low protein diets in patients with chronic kidney disease: Surum and urine DEXA and amino acid profiles. Anti-Aging Med. 2010; 7(2): 7-13. doi: 10.3793/ jaam.7.7

19. Watanabe S. Low-protein diet for the prevention of renal failure. Proc Japan Acad Ser B. 2017; 93(1): 1-9. doi: 10.2183/pjab.93.001

20. Watanabe S, Hirakawa A, Nishijima C, et al. Food as medicine: The new concept of "medical rice". Adv Food Technol Nutr Sci Open J. 2016; 2(2): 38-50. doi: 10.17140/AFTNSOJ-2-129

21. Goto A, Noda M, Inoue M, Goto M, Charvat H. Increasing number of people with diabetes in Japan: Is this trend real? Intern Med. 2016; 55: 1827-1830. doi: 10.2169/internalmedicine.55.6475

22. World Health Organization 2016. Global report on diabetes. ISBN 9789241565257 (NLM classification WK 810).

23. Herman WH, Ma Y, Uwaifo G, et al; Diabetes Prevention Program Research Group. Differences in A1c by race and ethnicity among patients with impaired glucose tolerance in the Diabetes Prevention Program. Diabetes Care. 2007 30: 2453. doi: 10.2337/ dc06-2003

24. Jeon CY, Lokken RP, Hu FB, van Dam RM. Physical activity of moderate intensity and risk of type 2 diabetes: A systematic review. Diabetes Care. 2007; 30: 744-752. doi: 10.2337/dc06-1842

25. Nakade M, Aiba N, Suda N, et al; SCOP Group. Behavioral change during weight loss program and one-year follow-up: Saku 
Control Obesity Program (SCOP in Japan). Asia Pac J Clin Nutr. 2012; 21(1): 22-34.

26. Ismail-Beigi F, Moghissi E, Kosiborod M, Inzucchi SE. Shifting paradigms in the medical management of type 2 diabetes: Reflections on recent cardiovascular outcome trials. J Gen Intern Med. 2017; 32: 1044-1051. doi: 10.1007/s11606-017-4061-7

27. Handelsman Y, Bloomgarden ZT, Grunberger G, et al. American association of clinical endocrinologists and American college of endocrinology_clinical practice guidelines for developing a diabetes mellitus comprehensive care plan-2015. Endocr Pract. 2015; 21: 1-87. doi: 10.4158/EP15672.GL

28. The Management of Type 2 Diabetes Mellitus in Primary Care Work Group. VA/DoD clinical practice guideline for the manage- ment of type 2 diabetes mellitus in primary care. Version 5.0. April 2017. Web site. https://www.healthquality.va.gov/guidelines/ CD/diabetes/VADoDDMCPGFinal508.pdf. Accessed August 8, 2017.

29. Watanabe S, Mizuno S, Hirakawa A. Effects of brown rice on obesity: GENKI Study I (Cross sectional epidemiological study). $J$ Obesity Metab Dis. (Under peer review process)

30. Watanabe S, Mizuno S, Takahashi M, Hirakawa A. Diabetes and obesity-from GENKI Study. Clin Funct Nutr. 2018; 10(2): 79-86.

31. Hirakawa A, Melby M, Watanabe S. Comprehensive Food Labeling for Obesity Control. Advances in Obesity, Weight Management \& Control. 2016; 4(3): 00088. doi: 10.15406/aowmc.2016.04.00088 